Revista do Departamento de Geografia
Universidade de São Paulo
www.revistas.usp.br/rdg

\title{
Perdas de Solo, Razão de Perdas de Solo e Fator Cobertura e Manejo da Cultura de Cana-de-Açúcar: Primeira Aproximação
}

\author{
Soil Losses, Soil Loss Ratio and Cover
Management Factor of Sugarcane: A First Approach \\ Soil Losses, Soil Loss Ratio and Cover
Management Factor of Sugarcane: A First Approach
}

Edvania Aparecida Corrêa

Universidade Estadual Paulista "Júlio de Mesquita Filho"

edvania.correa86@gmail.com

Isabel Cristina Moraes

Universidade Estadual Paulista "Júlio de Mesquita Filho"

bel.moraes@gmail.com

Sergio dos Anjos Ferreira Pinto

Universidade Estadual Paulista "Júlio de Mesquita Filho"

sanjos@rc.unesp.br

Cenira Maria Lupinacci

Universidade Estadual Paulista "Júlio de Mesquita Filho"

cenira@rc.unesp.br

Recebido (Received): 24/06/2016 Aceito (Accepted): 13/09/2016 DOI: $10.11606 /$ rdg.v2i0.116671

Resumo: O objetivo desse artigo é discutir a questão da erosão em áreas de cultivo de cana de açúcar. Assim, foram determinadas as perdas de solo, a razão de perdas de solo (RPS) e os valores do fator cobertura e manejo (fator C) da Equação Universal de Perdas de solo (Universal Soil Loss Equation - USLE) para a cultura de cana-de-açúcar, cultivada em solos arenosos e argilosos e em diferentes condições de relevo e de manejo. Para obter dados visando atingir tal objetivo, foram utilizadas técnicas experimentais, com a instalação de 8 parcelas de monitoramento de erosão hídrica do solo (2x10 metros). Durante um ano agrícola foram coletadas amostras de água e sedimento, sendo realizada a quantificação do material erodido. Nas parcelas instaladas em Cambissolos Háplicos de textura areia franca/franco arenosa, declividades de $12 \%$ e $15 \%$ e cultivadas com cana planta sob preparo convencional, as perdas foram de 49 e $84 \mathrm{t}^{-1} \mathrm{ha}^{-1}$ ano respectivamente e o fator $C$ médio foi de 0,424 . Nas parcelas instaladas em Argissolo Vermelho Amarelo, com declive de 5\% e em Cambissolo Háplico, com declive de $11 \%$, ambos de textura argilosa e cultivados com cana soca de $3^{\circ}$ corte sob plantio direto, as perdas foram de 0,797 e $3,684 \mathrm{t}^{-1} \mathrm{ha}^{-1}$ ano e o fator $\mathrm{C}$ de $0,234 \mathrm{e}$ 0,130 respectivamente. Os valores de RPS variaram de 0,393 a 0,521 (do plantio até 3 meses) e de 0,051 a 0,449 (período de 10 a 12 meses) nos solos arenosos, e de 0,081 a 1,109 (plantio até 3 meses) e de 0,041 a 0,069 ( 10 a 12 meses) nos solos argilosos. Os diferentes tipos de solos, relevo e manejo presentes nas parcelas resultaram em valores de perdas, RPS e Fator C discrepantes. Neste sentido, tem-se a necessidade de maior atenção à variabilidade e à sensibilidade destes parâmetros na modelagem de perdas de solo por erosão hídrica em áreas cultivadas com cana-de-açúcar.

Palavras-Chave: Erosão Hídrica; Declividade; Fator C; USLE.

\begin{abstract}
This study aimed to discuss the issue of erosion in areas of sugar cane cultivation. So they were determined soil losses, the soil loss ratio (SLR) and the values of the cover management factor (factor C) of Universal Soil Loss Equation (USLE) for the sugarcane located in sandy and clay soils and under different conditions of relief and management. Eight plots of monitoring soil erosion (2x10 meters) were installed. During the period of the 1 crop year, were collected samples of water and sediment and quantified the eroded material. In the plots installed in Cambisol with sand loam/loam sand texture, slopes of 12 and $15 \%$ and cultivated with plant cane under tillage, the losses were 49.042 and $84.851 \mathrm{t}-1$ ha-1 year, respectively, and the $C$ average factor was of 0.424. In the plots installed in Lixisol, with slope of 5\% and Cambisol, with slope of $11 \%$, both clayey and cultivated with third ratoon cane under no-tillage, the losses were 0.797 and 3.684 t 1 ha-1 year and the C factor of 0.234 and 0.130 respectively. The SLR values ranged from 0.393 to 0.521 (planting up to 3 months) and from 0.051 to 0.449 (period of 10 to 12 months) in sandy soil, and 0.081 to 1.109 (planting up to 3 months) and from 0.041 to 0.069 (10 to 12 months) in clayey soils. Different soil types, relief and management present in the plots resulted in discrepant values of soil loss, SLR and Factor C. In this sense, there is the need for greater attention to the variability and sensitivity of these parameters in the modeling of soil loss by water erosion in areas cultivated with sugarcane.

Keywords: Water Erosion; Slope; Factor C; USLE.
\end{abstract}




\section{INTRODUÇÃO}

Devido ao investimento em fontes de energias alternativas ao uso de combustíveis fósseis, tem-se verificado no cenário nacional, e mais especificamente no estado de São Paulo, a expansão da cultura de cana-de-açúcar. Nos últimos 30 anos, a expansão, em termos de área plantada, foi de $166 \%$ no cenário brasileiro e de $230 \%$ no cenário paulista (UNICA, 2015).

Corrêa et al. (2015) verificaram que a ampliação dos canaviais paulistas está ocorrendo em áreas impróprias aos cultivos anuais. Algumas regiões têm apresentado um aumento dos processos erosivos decorrentes da inexistência de um planejamento no uso da terra. Neste sentido, a expansão da área plantada deve ser avaliada considerando as condições de fragilidade natural de cada paisagem, visando averiguar as reais vantagens na produção de derivados de cana-de-açúcar.

Dentre os estudos de erosão do solo no cenário mundial, e também no Brasil, destacam-se aqueles relacionados à utilização de modelos preditivos. Em especial, a Equação Universal de Perdas de Solo (Universal Soil Loss Equation - USLE) compõe a maioria dos estudos de erosão do solo no mundo (GARCÍA RUIZ et al., 2015).

A USLE é constituída pelos fatores relacionados à erosividade (fator R), erodibilidade (Fator K), fator topográfico (composto pela declividade e pela extensão das vertentes, Fator LS), cobertura vegetal (Fator C) e práticas conservacionistas (Fator P). No processo erosivo, a cobertura vegetal e o manejo (Fator C) constituem o segundo fator de maior importância, sendo o relevo (fator LS) o de maior influência nas perdas de solo (VAN DER KNIJFF et al., 2000). Assim, as modificações no uso e manejo do solo são agentes intensificadores dos processos de erosão hídrica do solo.

O fator C da USLE é o somatório dos produtos da razão de perda de solo (RPS) pela fração do índice de erosividade (FEI $\mathrm{FI}_{30}$ ) de cada estágio da cultura (WISCHMEIER; SMITH, 1978). A RPS é a relação entre as perdas de solo da parcela com o cultivo em estudo e as perdas de solo da parcela padrão, a qual é mantida descoberta durante todos os estágios da cultura (PROCHNOW, 2003). O fator C varia de zero a um, aproximando-se de zero nos sistemas de manejo conservacionistas, e de um, nos sistemas não conservacionistas (PROCHNOW et al., 2005). Portanto, o fator C é resultado de uma integração de fatores (clima, solo, topografia, prática de manejo adotada) que influenciam no desenvolvimento vegetal e que resultam num valor numérico específico para cada região onde o mesmo foi determinado (DA SILVA; SCHULZ, 2001). Este é o fator de maior dificuldade de obtenção devido a grande possibilidade de combinações de práticas de manejo, instalações e rotações de culturas, feitas simultaneamente ou separadamente para uma mesma área (DE MARIA; LOMBARDI NETO, 1997).

Apesar das inúmeras especificidades, o que se verifica no cenário nacional e internacional é a constante aplicação de modelos preditivos utilizando base de dados do fator $\mathrm{C}$ determinados para condições distintas daquelas modeladas (POESEN et al., 2003; BOARDMAN, 2006). A carência de estudos do comportamento erosivo dos solos brasileiros, em diferentes condições naturais e em diferentes manejos, é um dos maiores obstáculos para a concepção e a melhoria dos modelos para as condições tropicais.

Dentre os trabalhos realizados no Brasil visando a determinação das razões de perdas de solo e fator C para a cultura da cana-de-açúcar, destacam-se as pesquisas de Lombardi Neto e Bertoni (1975), Donzeli et al. (1992), De Maria et al. (1994), Cavalieri (1998) e Bertoni e Lombari Neto (2010).

Assim, há a necessidade de estudos que avaliem os impactos da expansão da cultura de cana-deaçúcar em termos de erosão hídrica, bem como que estimem o fator $\mathrm{C}$ dos canaviais em diferentes condições físicas de paisagem. Neste sentido, o objetivo do presente trabalho foi o de determinar, sob chuva natural, as perdas de solo, a RPS e os valores do fator C para a cultura de cana-de-açúcar praticada em solos arenosos e argilosos e em diferentes condições de relevo e de manejo.

\section{CARACTERIZAÇÃO DAS ÁREAS DE ESTUDO}

Parcelas experimentais de monitoramento de erosão foram instaladas na bacia hidrográfica do ribeirão do Jacutinga e do córrego Monjolo Grande, sendo a primeira localizada no município de Rio Claro e a segunda no município de Ipeúna, ambas no centro-leste do estado de São Paulo (Figura 1). Estas áreas foram selecionadas por apresentarem semelhanças em termos de área e características de uso da terra, mas com condições pedológicas e topográficas distintas. 


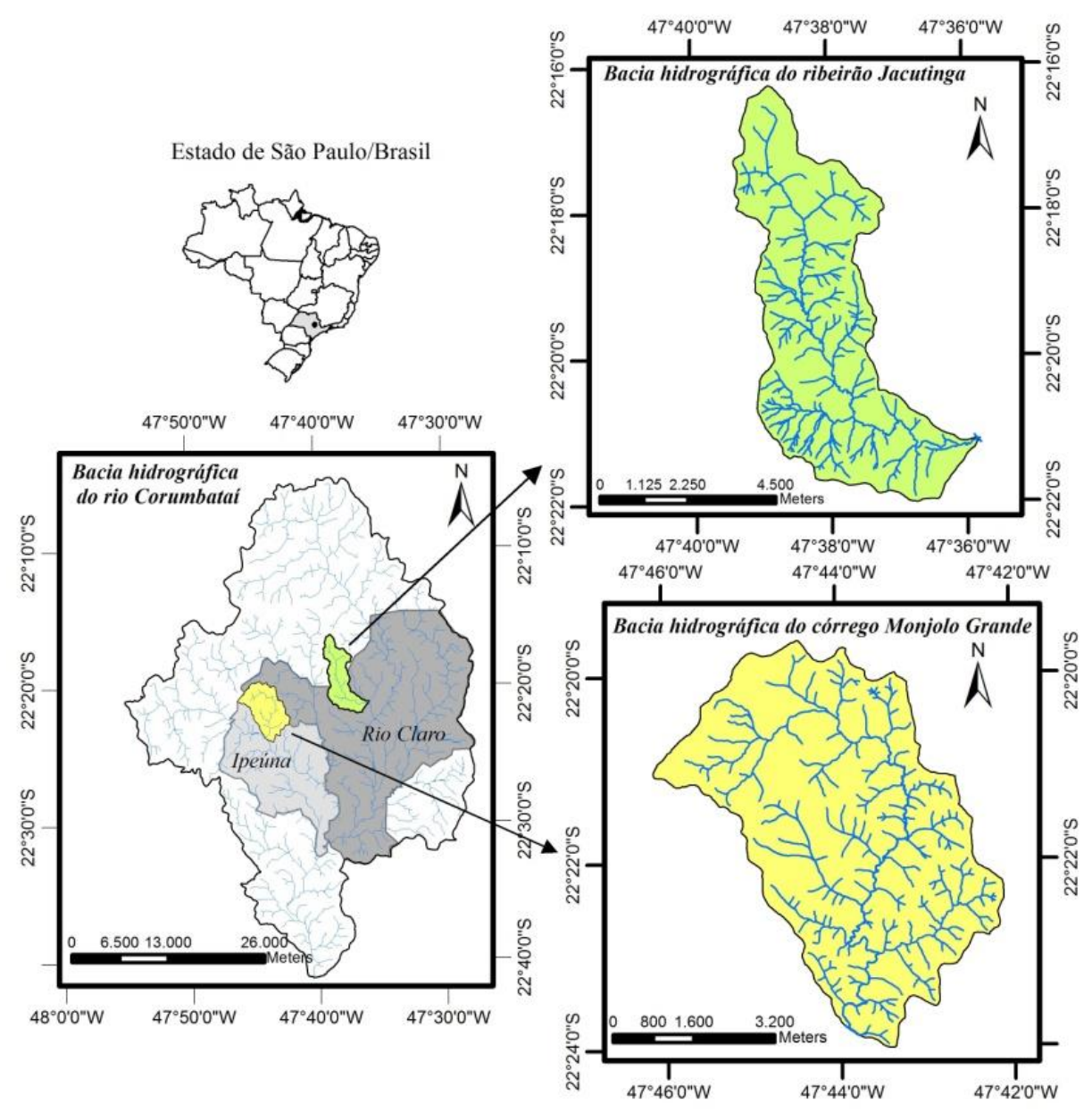

Figura 1: Localização das áreas de estudo.

As áreas de estudo estão inseridas na província geomorfológica denominada Depressão Periférica Paulista. Apresentam topografia pouco acidentada, altitudes predominantes variando de 600 a 720 metros, com relevo dominantemente formado por colinas, interflúvios com áreas de $1 \mathrm{~km}^{2} \mathrm{a} 4 \mathrm{~km}^{2}$, topos aplainados e vertentes com perfis convexos e retilíneos. No entanto, nas bordas ocidentais na bacia hidrográfica do córrego Monjolo Grande, as quais estão localizadas no front das cuestas arenito basáltica, ocorrem pequenos morros residuais com altitudes alcançando a cota de 900 metros, vertentes de alta declividade e drenagem densa e entalhada.

As bacias hidrográficas são enquadradas no tipo climático Cwa, conforme a classificação zonal de Köppen, podendo ser associado ao clima subtropical, com inverno seco e verão chuvoso.

No banco de dados do Departamento de Águas e Energia Elétrica (DAEE) do estado de São Paulo, os postos pluviométricos mais próximos às áreas de estudo são D4-036 e D4-012 (prefixo DAEE). O posto D4-036, denominado Graúna, está situado no município de Itirapina-SP e distante $10 \mathrm{~km}$ em linha reta da bacia hidrográfica do córrego Monjolo Grande. Apresenta série histórica de 1937 a 2015. Já o posto D4-012 denominado Rio Claro, distante $11 \mathrm{~km}$ em linha reta da bacia hidrográfica do ribeirão Jacutinga, encontra-se situado no município de Rio Claro - SP e apresenta uma série histórica de 1936 a 2015.

O posto D4-036 (Graúna) apresenta os maiores valores médios de chuva nos meses de dezembro e janeiro (221,73 mm e 257,63 mm, respectivamente) e mínimos médios mensais nos meses de julho e agosto (29,02 mm e 25,67 mm, respectivamente). O total de precipitação no ano apresenta a média de 1436,86 mm. O posto D4-012 também apresenta os maiores valores médio de chuva nos meses de dezembro e janeiro $(213,5 \mathrm{~mm}$ e $246,1 \mathrm{~mm})$ e mínimos mensais nos meses de julho e agosto $(29,88 \mathrm{~mm}$ e $28,17 \mathrm{~mm}$ respectivamente). O total de precipitação no ano apresenta a média de $1379,7 \mathrm{~mm}$. A maior quantidade de chuvas incidentes sobre a bacia hidrográfica do córrego Monjolo Grande se deve ao efeito orográfico advindo da maior proximidade com o relevo de cuestas. Assim, tem-se maior quantidade de precipitações e, consequentemente, maior potencial erosivo das chuvas na bacia hidrográfica do córrego Monjolo Grande. 
A bacia hidrográfica do ribeirão Jacutinga é tributária da bacia do rio Corumbataí, no baixo curso do Rio Piracicaba (SP) e compreende área aproximada de $28,9 \mathrm{~km}^{2}$. Verifica-se o predomínio de Argissolos Vermelho Amarelos e Cambissolos Háplicos, os quais possuem como material de origem os argilitos da formação Corumbataí localizados predominantemente no médio e baixo curso. Em menor expressão tem-se a ocorrência dos Neossolos Quartzarênicos tendo como material de origem os arenitos de granulação fina e média da formação Pirambóia ocorrentes no alto curso (CORRÊA, 2016). Quanto aos processos de erosão hídrica do solo, Moraes (2014), a partir da aplicação da Equação Universal Perdas de Solo (EUPS), demonstrou que as áreas mais susceptíveis estão localizadas junto às nascentes, em relevo de maior declividade. Também nas áreas de transição entre unidades pedológicas distintas, devido ao maior impedimento de drenagem ocasionado pelo aumento dos teores de argila em superfície e subsuperfície, temse redução das taxas de infiltração com maior susceptibilidade aos processos erosivos.

A bacia hidrográfica do córrego Monjolo Grande é tributária do rio Passa Cinco, pertencente à bacia do rio Corumbataí, no baixo curso do rio Piracicaba (SP), compreendendo área aproximada de $28 \mathrm{~km}^{2}$. Há o predomínio de Neossolos Quartzarênicos nos interflúvios e de Argissolo Vermelho Amarelo nas médias e baixas vertentes, com declividades de até $20 \%$. Nas áreas localizadas próximas ao front das cuestas arenito basáltica e nos locais de maiores declividades localizados ao longo dos canais de $1^{\circ}$ ordem, tem-se a ocorrência de Neossolos Litólicos e Cambissolos (CORRÊA, 2016). Todos os solos desta área apresentam textura variando de média a arenosa, os quais são originados predominantemente dos arenitos das formações Botucatu e Pirambóia. Quanto à predisposição natural a erosão, esta bacia apresenta $40 \%$ de sua área com perdas acima de 100 ton ha ${ }^{-1} \mathrm{ano}^{-1}$. Estas áreas localizam-se em relevos ondulados a fortemente ondulados, onde os valores de declividade são superiores a $8 \%$ e há a ocorrência de solos mais vulneráveis aos processos de erosão hídrica, como Argissolos Vermelho Amarelos, Cambissolos e Neossolos Litólicos (CORRÊA et al., 2015).

Como em todo o estado de São Paulo, as áreas de estudo têm sido submetidas à intensa ocupação antrópica, particularmente resultante da expansão do cultivo da cana-de-açúcar e de áreas de pastagens, como indicado em Pereira e Pinto (2007). Corrêa et al. (2015) identificaram, no período de 1988 a 2013, expansão de $80 \%$ da cultura de cana-de-açúcar na bacia hidrográfica do córrego Monjolo Grande em áreas não adequadas a culturas anuais e de maior susceptibilidade a erosão hídrica do solo. Também, Couto Junior (2014) identificou na bacia hidrográfica do ribeirão Jacutinga, 53,5\% e 16,4\% de ocupação por pastagem e cana-de-açúcar, respectivamente, indicando a elevada importância destes usos no cenário econômico local.

\section{MATERIAL E MÉTODOS}

Foram selecionados, em ambas as bacias de estudo, locais com as classes de declives de maior ocorrência e cujo uso fosse cana-de-açúcar. Foram instaladas 8 parcelas de monitoramento de erosão do solo de $20 \mathrm{~m}^{2}$ (2,00 x 10,00 metros), com a maior dimensão no sentido do declive, sendo 4 na bacia hidrográfica do córrego Monjolo Grande (C1M, C2M, SD1M e SD2M) e 4 na bacia hidrográfica do ribeirão Jacutinga (C1J, C2J, SD1J e SD2J). A definição das dimensões das parcelas de $20 \mathrm{~m}^{2}$ foi devido à implantação em áreas de terceiros. As parcelas foram instaladas nas unidades taxonômicas de solo de maior ocorrência e em propriedades onde o acesso e a experimentação fossem autorizados (Figura 2 e Figura 3). A instalação das parcelas em distintas classes de solos, com caraterísticas físicas diferenciadas, especialmente relacionadas às classes texturais, se deve a busca por informações que viabilizassem reconhecer a variabilidade do comportamento erosivo de acordo com tais classes.

As parcelas foram delimitadas por chapas galvanizadas de $40 \mathrm{~cm}$ de altura, sendo $10 \mathrm{~cm}$ enterrados no solo e o restante acima da superfície. Na parte inferior das parcelas foram instaladas calhas de Gerlach (GUERRA, 2005) e tanques armazenadores de água. Uma descrição mais detalhada das características físicas dos locais de implantação é apresentada na Tabela 1.

Em ambas as áreas de estudo, as parcelas com cana-de-açúcar foram implantadas após a colheita seguida de plantio, em sistema convencional de preparo do solo o qual consiste no revolvimento de camadas superficiais do solo para reduzir a compactação. Foi realizada gradagem pesada, intermediária e niveladora. As práticas conservacionistas aplicadas foram plantio em curva de nível e construção de terraços. 

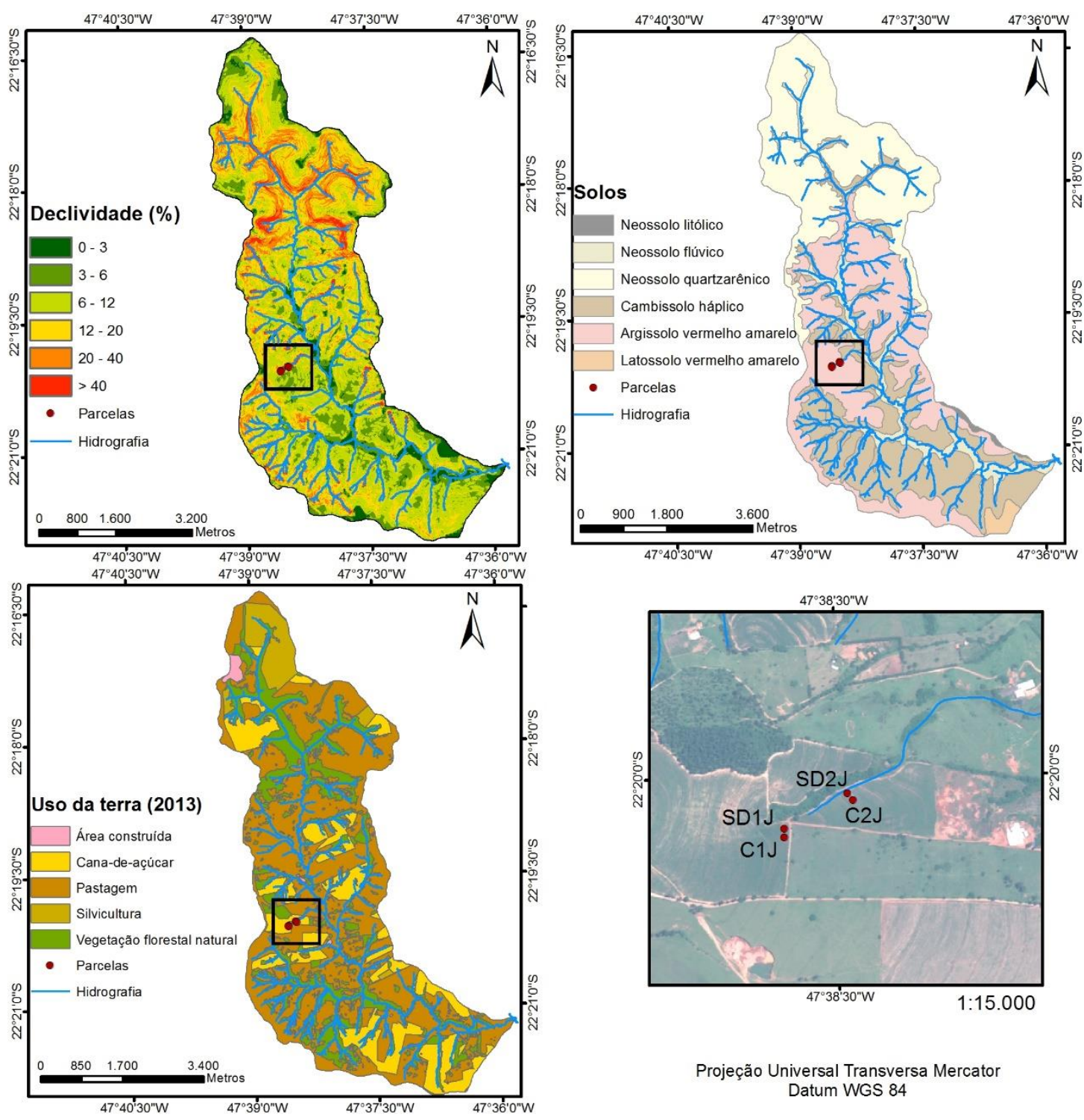

Projeção Universal Transversa Mercator Datum WGS 84

Figura 2: Declividade, solos, uso da terra com destaque para a localização das parcelas na bacia hidrográficas do ribeirão Jacutinga.

O monitoramento das perdas de solo por erosão hídrica ocorreu no período de junho de 2013 a maio de 2014 na bacia hidrográfica do ribeirão Jacutinga e de agosto de 2013 a julho de 2014 na bacia hidrográfica do córrego Monjolo Grande. A ausência de replicação dos tratamentos nos estudos de erosão com chuva natural deve-se à dificuldade de obter áreas com as mesmas condições de solo e relevo, presença de limitações operacionais para a coleta dos dados e de compatibilidade com as operações mecanizadas da cultura, além do uso de terrenos particulares. Embora os dados sejam de 1 ano agrícola, estes possuem a sua importância visto a carência de estudos desta natureza no cenário brasileiro.

As parcelas com cana-de-açúcar localizadas na bacia hidrográfica do ribeirão Jacutinga foram compostas pela variedade de ciclo médio, $3^{\circ}$ colheita. A última colheita foi realizada mecanicamente em junho de 2013, sendo mantidos os restos vegetais na superfície.

Já as parcelas com cana-de-açúcar localizadas na bacia hidrográfica do córrego Monjolo Grande foram compostas por cana planta de variedade de ciclo médio, sendo o plantio realizado em julho de 2013. Devido à recente reforma dos talhões, foram mantidos poucos restos vegetais de culturas anteriores na superfície. A última colheita, antes da reforma dos talhões, foi realizada manualmente devido às características de declividade do terreno. 

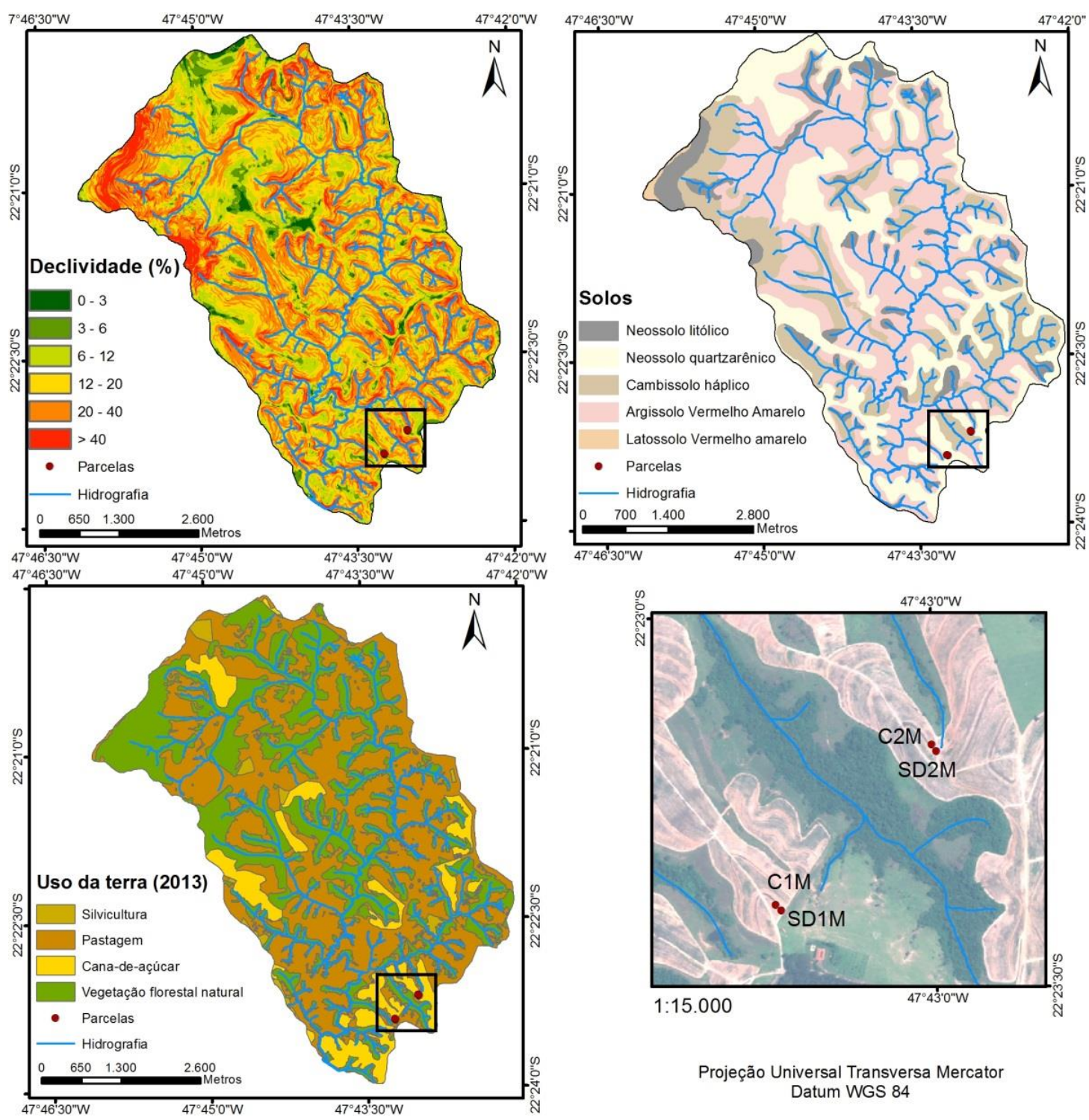

Projeção Universal Transversa Mercator Datum WGS 84

Figura 3: Declividade, solos, uso da terra com destaque para a localização das parcelas nas bacias hidrográficas do córrego Monjolo Grande.

Tabela 1: Características das parcelas de monitoramento de erosão.

\begin{tabular}{|c|c|c|c|c|}
\hline & Parcela & Cobertura & Declividade & Solos \\
\hline \multirow{4}{*}{$\begin{array}{c}\text { Bacia } \\
\text { hidrográfica } \\
\text { do córrego } \\
\text { Monjolo } \\
\text { Grande }\end{array}$} & $\mathrm{C} 1 \mathrm{M}$ & Cana-de-açúcar & $12 \%$ & \multirow{2}{*}{$\begin{array}{l}\text { Cambissolo háplico, Ta eutrófico, típico, A } \\
\text { moderado, textura franco arenosa (CX) }\end{array}$} \\
\hline & SD1M & Solo exposto & $12 \%$ & \\
\hline & $\mathrm{C} 2 \mathrm{M}$ & Cana-de-açúcar & $15 \%$ & \multirow{2}{*}{$\begin{array}{c}\text { Cambissolo háplico, Ta distrófico, típico, A } \\
\text { moderado, textura areia franca (CX) }\end{array}$} \\
\hline & SD2M & Solo exposto & $15 \%$ & \\
\hline \multirow{4}{*}{$\begin{array}{c}\text { Bacia } \\
\text { hidrográfica } \\
\text { do ribeirão } \\
\text { Jacutinga }\end{array}$} & $\mathrm{C} 1 \mathrm{~J}$ & Cana-de-açúcar & $5 \%$ & \multirow{2}{*}{$\begin{array}{l}\text { Argissolo Vermelho Amarelo, Ta eutrófico, } \\
\text { A moderado textura argilosa (PVA) }\end{array}$} \\
\hline & SD1J & Solo exposto & $5 \%$ & \\
\hline & $\mathrm{C} 2 \mathrm{~J}$ & Cana-de-açúcar & $11 \%$ & \multirow{2}{*}{$\begin{array}{l}\text { Cambissolo háplico, eutrófico, típico, A } \\
\text { moderado, textura argilosa (CX) }\end{array}$} \\
\hline & $\mathrm{SD} 2 \mathrm{~J}$ & Solo exposto & $11 \%$ & \\
\hline
\end{tabular}


As parcelas com solo exposto foram implantadas visando à comparação da dinâmica do processo erosivo entre as diferentes condições de cobertura, bem como a determinação das RPS e do fator C da USLE. Estas foram alocadas ao lado das parcelas com cana-de-açúcar (Figura 4) e mantidas constantemente sem nenhum tipo de vegetação e crostas, conforme orientação de Wischmeier e Smith (1978, p. 8).
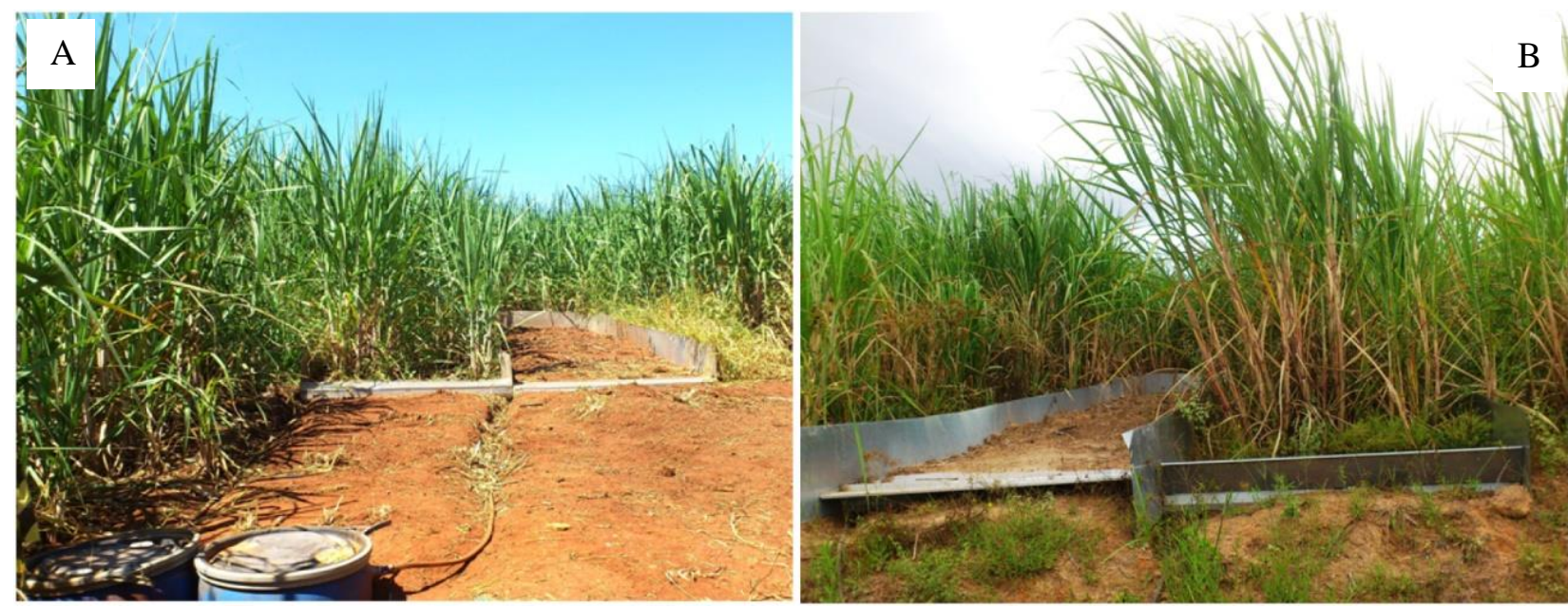

Figura 4: Parcelas de monitoramento de erosão com solo descoberto e cultura de cana-de-açúcar: (A) Parcelas localizadas na bacia hidrográfica do ribeirão Jacutinga - C1J e SD1J. (B) Parcelas localizadas na bacia hidrográfica do córrego Monjolo Grande - C1M e SD1M (Fonte: Edvania Ap. Corrêa).

Amostras de água e de sedimentos foram coletadas após cada evento pluviométrico, conforme metodologia descrita em Cogo (1978). Em cada evento erosivo, os materiais retidos nas calhas foram coletados e adicionados ao material armazenado nos tanques (Figura 5). Após a homogeneização de todo o material (sedimento e água), foram coletadas amostras de aproximadamente $500 \mathrm{ml}$. Ainda em campo, foram registradas as alturas das enxurradas no interior dos tanques coletores $(\mathrm{cm})$ a partir da inserção do metro rígido. Posteriormente, com os valores dimensionais dos tanques coletores, foram obtidos os valores do volume de água oriunda do escoamento superficial em cada parcela.

A quantificação de todo o material proveniente do processo erosivo foi realizada pelo método da evaporação (CARVALHO et al., 2000). As amostras ficaram em repouso por 24 horas, visando à decantação do sedimento. $\mathrm{O}$ excesso de líquido foi passado em peneira de $0,052 \mathrm{~mm}$. O material restante foi levado à estufa em temperatura de $60^{\circ} \mathrm{C}$, visando à evaporação e secagem do sedimento para posterior quantificação de sedimento seco. Após a secagem das amostras, foram computados os valores de perda de solo $\left(\mathrm{g} / \mathrm{m}^{2}\right)$ para cada parcela, considerando o volume total de água nos tanques.

Com o intuito de avaliar comparativamente os dados obtidos com as parcelas, foram ainda utilizados outros parâmetros. Assim, os valores de tolerância de perdas de solo e erodibilidade foram obtidos a partir de Corrêa et al. (2015). Estes autores utilizaram o método proposto por Denardin (1990) para a estimativa da erodibilidade e de Lombardi e Bertoni (1975), modificado por Bertol e Almeida (2000), para a estimativa da tolerância de perdas.

Os dados de precipitação, em intervalos de 5 minutos, foram coletados na estação meteorológica modelo Davis Vantage Pro 2 Plus instalada na bacia hidrográfica do Ribeirão Monjolo Grande e no posto pluviográfico D4-112 pertencente ao Departamento de Águas e Energia Elétrica (DAEE) do governo do estado de São Paulo. O posto D4-112M foi utilizado para a estimativa de perdas da bacia hidrográfica do ribeirão Jacutinga visto a sua maior proximidade com essa área de estudo. 


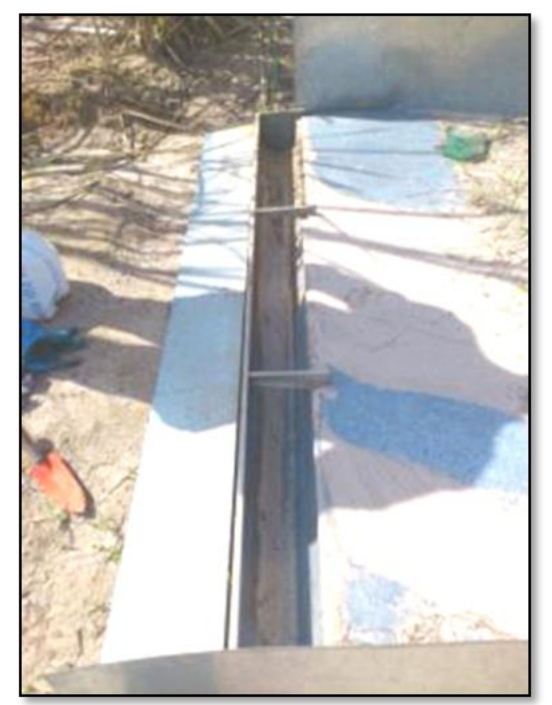

Figura 5: Coleta do material retido na calha coletora (Fonte: Edvania Ap. Corrêa).

Para a seleção das chuvas erosivas, foram seguidos os seguintes critérios: chuvas com precipitação maior ou igual a $10,0 \mathrm{~mm}$; chuvas com precipitação menor do que $10,0 \mathrm{~mm}$ se sua quantidade em 15 minutos for igual ou maior a $6,0 \mathrm{~mm}$; chuvas com energia cinética total, maior ou igual a 3,6 MJ/ha (WISCHMEIER; SMITH, 1978).

A definição das chuvas individuais foi realizada conforme Cabeda (1976). Eventos pluviométricos separados por intervalo igual ou superior a 6 horas e com total pluviométrico superior a $10 \mathrm{~mm}$ foram classificados como chuva individual. Também eventos pluviométricos separados por um intervalo de 6 horas ou mais e com até $1,00 \mathrm{~mm}$ de precipitação neste período foram classificados como chuva individual. Com base em Lombardi Neto (1977) e Bertoni e Lombardi Neto (2010) foi obtida a energia cinética das chuvas, conforme a Equação 1.

$$
E_{c}=0,119+0,0873 \log \mathrm{I}
$$

sendo:

$\mathrm{E}_{\mathrm{c}}=$ energia cinética em MJ/ha-mm;

$\mathrm{I}=$ intensidade da chuva $\mathrm{em} \mathrm{mm} / \mathrm{h}$.

Para cada chuva erosiva, foi determinada a intensidade máxima em 30 minutos $\left(\mathrm{I}_{30}\right)$, conforme Wischmeier e Smith (1978). O índice de erosividade de cada evento selecionado foi obtido a partir da formulação proposta por Bertoni e Lombardi Neto (2010) (Equação 2). A erosividade mensal e anual foi obtida a partir da somatória da erosividade de todas as chuvas consideradas erosivas.

$$
\mathrm{EI}_{30}=\mathrm{Ec} \times I_{30}
$$

sendo:

$\mathrm{EI}_{30}=$ índice de erosão em $\mathrm{MJ} / \mathrm{ha} \cdot \mathrm{mm} / \mathrm{h}$;

$\mathrm{Ec}=$ energia cinética da chuva em MJ/ha-mm;

$\mathrm{I}_{30}=$ intensidade máxima em 30 minutos $(\mathrm{mm} / \mathrm{h})$.

Considerando os valores de porcentagem da cobertura do solo, conforme recomendados pela Food and Agriculture Organization of the United Nations - FAO (DOORENBOS; PRUITT, 1977; DOORENBOS; KASSAM, 1979), foram estabelecidos 5 períodos do ano agrícola para a cultura da cana-de-açúcar a partir do plantio ou da colheita anterior: de 0 a 3; de 3 a 4; de 4 a 9, de 9 a 10; e de 10 a 12 meses. 
Para a determinação da razão de perda de solo (RPS), foi realizado o ajuste das perdas de solo de cada parcela para o declive de $0,09 \mathrm{~m} \mathrm{~m}^{-1}$, conforme proposto por Wischmeier e Smith (1978). O ajuste foi realizado multiplicando os valores de perdas de cada parcela pelo valor resultante Equação 3.

$$
\mathrm{s}=0,065+4,56 \cdot \operatorname{sen} \theta+65,41 .(\operatorname{sen} \theta)^{2}
$$

onde:

$\mathrm{S}=$ fator grau do declive da USLE, definido pela relação de perda de solo entre uma parcela com declive qualquer e outra com declive de $0,09 \mathrm{~m} \mathrm{~m}^{-1}$;

$\theta=$ ângulo de declive do terreno (radianos).

Para cada estágio agrícola foi utilizada a Equação 4 para o cálculo da RPS (DE MARIA; LOMBARDI NETO, 1997):

$$
\mathrm{RPTi}=\frac{\mathrm{ptC}}{\mathrm{ptP}}
$$

onde:

RPSi = razão de perdas de solo por estágio agrícola (i);

$\mathrm{ptC}=$ perdas de terra na parcela com cultura $\left(\mathrm{t} \mathrm{ha}^{-1}\right)$;

$\mathrm{ptP}=$ perdas de terra na parcela padrão mantida descoberta $\left(\mathrm{t} \mathrm{ha}^{-1}\right)$.

Para a determinação do Fator C de cada parcela, a RPS de cada estágio foi associada aos dados da distribuição da fração da erosividade ( $\left.\mathrm{FEI}_{30}\right)$, conforme De Maria e Lombardi Neto (1997) (Equação 5)

$$
\text { FatorC }=\sum_{\mathrm{i}=5}^{5} \mathrm{RPT} \frac{i \times \mathrm{Ri}}{\mathrm{Rt}}
$$

Onde:

$\mathrm{i}$ = estágio da cultura

RPSi = razão de perdas de solo no estádio i;

$\mathrm{Ri}=$ erosividade no estádio $\mathrm{i}$;

$\mathrm{Rt}=$ erosividade total.

\section{RESULTADOS E DISCUSSÃO}

No ano experimental, os meses com os maiores índices pluviométricos e que apresentaram redução dos totais de chuva em relação à média histórica foram dezembro/2013 e janeiro/fevereiro/2014. Na bacia do ribeirão Jacutinga, esta redução foi de $27 \%$ na comparação com a média histórica do posto D4-112. Já na bacia hidrográfica do córrego Monjolo Grande a redução foi $29 \%$ em relação à média histórica do posto D4036 (Figura 6). Tal redução no período avaliado é referente à maior seca incidente sobre o Sudeste brasileiro nos últimos 80 anos a qual afetou a segurança hídrica e energética dos estados de São Paulo e Rio de Janeiro (MARENGO, 2014).

Neste sentido, considerando que a erosividade está associada com a intensidade e duração das chuvas, na safra 2013/2014 as chuvas apresentaram menor potencial erosivo em relação a um ano típico. No ano 2013/2014, na bacia hidrográfica do córrego Monjolo Grande, foi obtida erosividade de 4.489,03 $\mathrm{MJ} /$ ha/ano. Já no posto D4-112, de maior proximidade com a bacia hidrográfica do ribeirão Jacutinga, a erosividade foi de 2.499,7 MJ/ha/ano para o mesmo período. Especialmente, na bacia do córrego Monjolo Grande, o efeito orográfico do relevo de cuestas atribui maior volume de chuvas e, portanto, maior potencial erosivo na área.

Utilizando dados climáticos de meados de 1930 até 2010, Lombardi Neto et al. (1980) e Moraes e Corrêa (2010), a partir da interpolação de dados de postos pluviométricos localizados no estado de São Paulo, apresentaram valores de erosividade variando de $6400 \mathrm{MJ} / \mathrm{ha} / \mathrm{ano}$ a $7800 \mathrm{MJ} / \mathrm{ha} / \mathrm{ano}$ para ambas as áreas de estudo. Assim, os menores valores de erosividade do período de 2013/2014 se devem às condições atípicas de precipitação ocorridas no estado de São Paulo. 


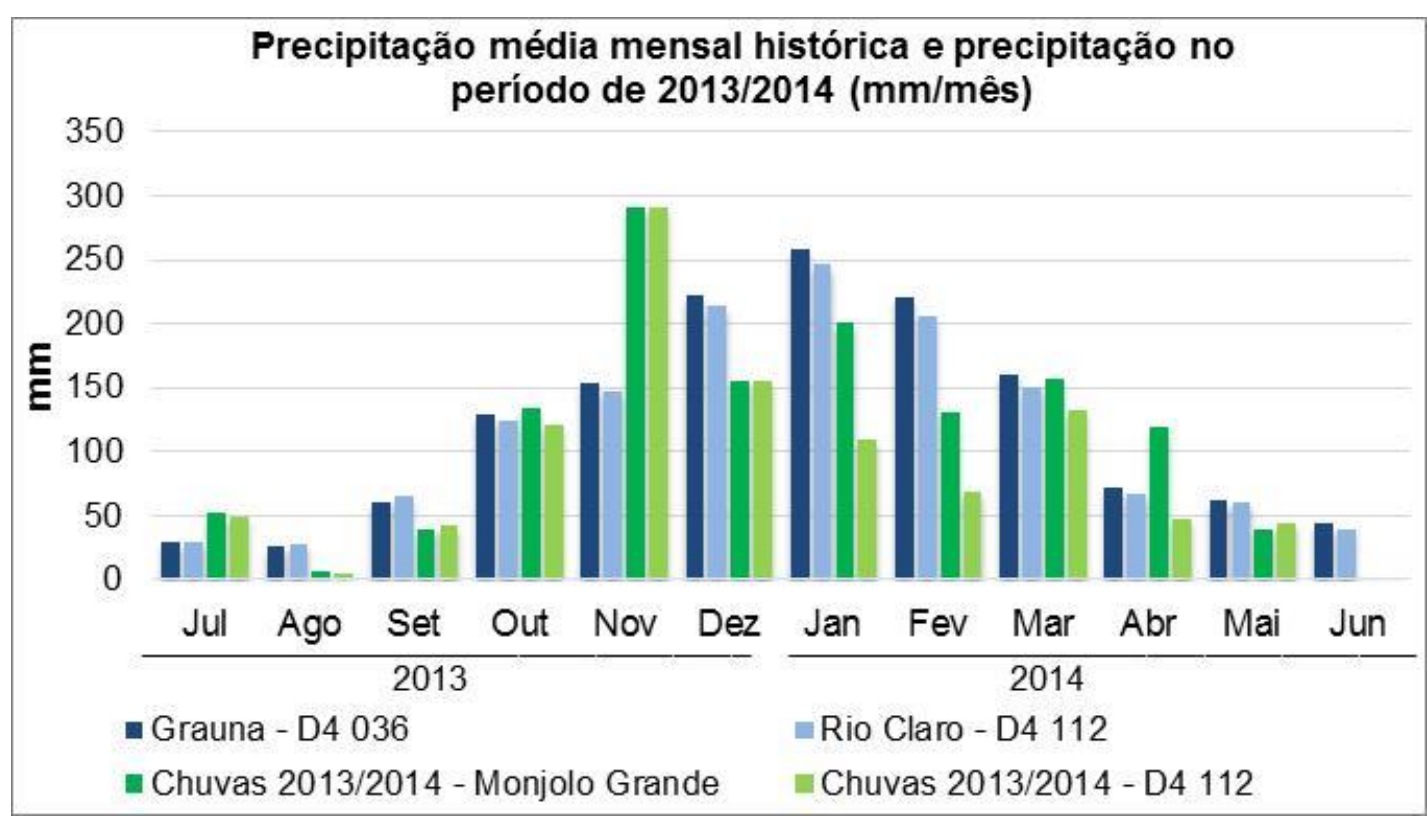

Figura 6: Precipitação média mensal histórica e precipitação no período de 2013/2014 (mm/mês).

Além do parâmetro de erosividade, os limites de tolerância de perda e as perdas de solo das parcelas experimentais foram calculados visando à análise do comportamento erosivo das áreas de estudo (Tabela 2).

Nos Cambissolos háplicos de textura arenosa da bacia hidrográfica do córrego Monjolo Grande, mesmo nas parcelas com cobertura vegetal, as perdas de solo foram elevadas quando comparadas aos limites de tolerância de perdas (Tabela 2).

Nas parcelas C1M e C2M as perdas foram de 49,09 $\mathrm{t} \mathrm{ha}^{-1} \mathrm{ano}^{-1}$ e de $84,85 \mathrm{t} \mathrm{ha}^{-1}$ ano $^{-1}$ respectivamente, sendo os limites de tolerância de perdas para estes solos inferiores a 5,25 $\mathrm{t} \mathrm{ha}^{-1} \mathrm{ano}^{-1}$ (tabela 2). As condições de maior declividade, elevada erodibilidade (tabela 3), presença de solos com menor profundidade, textura arenosa, presença reduzida de restos culturais na superfície associadas ao recente revolvimento do solo devido à reforma dos talhões e recente plantio foram os fatores responsáveis por essas elevadas perdas de solo.

Tabela 2: Tolerância de perda, perdas de solo e erosividade anual nas parcelas de monitoramento de erosão do solo.

\begin{tabular}{|c|c|c|c|c|c|}
\hline Parcelas & Solos & Declive & $\begin{array}{c}\text { Tolerância de } \\
\text { Perda }^{(1)}\end{array}$ & $\begin{array}{c}\text { Perda de } \\
\text { solo }\end{array}$ & Erosividade Anual \\
\hline & & $\%$ & ------ t ha ${ }^{-1}$ ano $^{-1}$ & 1 & MJ/ha/ano \\
\hline SD1M & $\mathrm{CX}$ & 12 & 5,25 & 74,03 & \multirow{4}{*}{4546,89} \\
\hline $\mathrm{C} 1 \mathrm{M}$ & $\mathrm{CX}$ & 12 & 5,25 & 49,04 & \\
\hline SD2M & $\mathrm{CX}$ & 15 & 3,35 & 206,53 & \\
\hline $\mathrm{C} 2 \mathrm{M}$ & $\mathrm{CX}$ & 15 & 3,35 & 84,85 & \\
\hline SD1J & PVA & 5 & 6,07 & 5,61 & \multirow{4}{*}{2621,08} \\
\hline $\mathrm{C} 1 \mathrm{~J}$ & PVA & 5 & 6,07 & 0,8 & \\
\hline SD2J & $\mathrm{CX}$ & 11 & 4,15 & 45 & \\
\hline $\mathrm{C} 2 \mathrm{~J}$ & $\mathrm{CX}$ & 11 & 4,15 & 2,76 & \\
\hline
\end{tabular}

${ }^{(1)}$ Adaptado de Corrêa (2016)

Nos Cambissolos háplicos de textura arenosa, a cultura da cana-de-açúcar não reduziu significativamente as perdas de terra em relação às perdas observadas nas parcelas desprovidas de vegetação. Na parcela C1M, a redução foi de $33,7 \%$ e na parcela C2M de 58,9\% para todo o ano experimental. Como consequência da elevada susceptibilidade erosiva destas áreas associada ao uso com cana-de-açúcar, em 
campo foram observadas grandes quantidades de material destacado e transportado pelo escoamento superficial (Figuras 7a e 7b). Tal resultado é crítico quando considerado que os maiores índices pluviométricos ocorrem nos meses em que muitas áreas destinadas ao cultivo de cana-de-açúcar do estado de São Paulo ainda se encontram parcialmente descobertas devido o período de entressafra. Por tratar-se de um ano atípico de chuva, no qual só entre os meses de dezembro a fevereiro houve redução de aproximadamente $30 \%$ dos totais pluviométricos, acredita-se que as perdas seriam superiores em um ano típico, tornando o cenário ainda mais alarmante (CORRÊA, 2016).
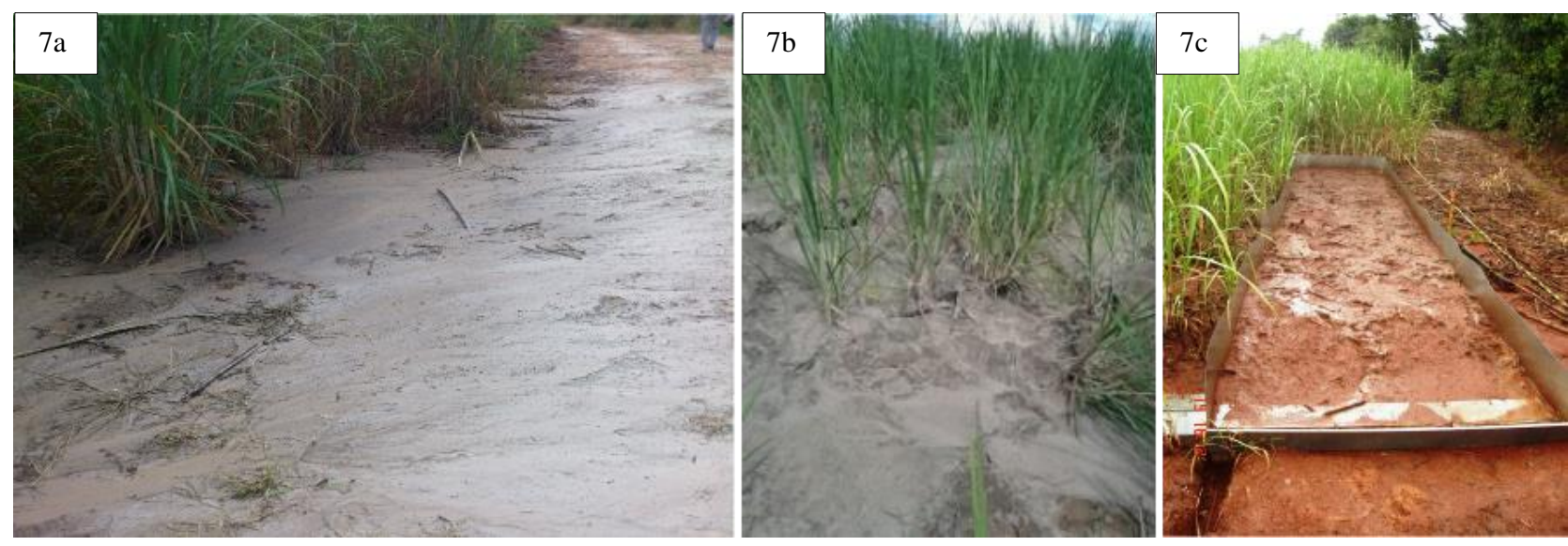

Figuras 7: (a) Erosão laminar após evento erosivo em culturas com cana-de-açúcar na bacia hidrográfica do córrego Monjolo Grande; (b) formação de selo superficial em evento pluviométrico na (c) parcela SD2J (bacia hidrográfica do ribeirão Jacutinga). Fonte: Edvania Corrêa.

Embora as perdas em todas as parcelas da bacia hidrográfica do córrego Monjolo Grande sejam muito superiores aos limites toleráveis, verificou-se elevada desproporção entre os valores observados em parcelas com usos similares. Neste sentido, as perdas quantificadas junto às parcelas C2M e SD2M foram superiores em $51 \%$ e $145 \%$ às perdas computadas junto às parcelas $\mathrm{C} 1 \mathrm{M}$ e $\mathrm{SD} 1 \mathrm{M}$, respectivamente. Os solos das parcelas C2M e SD2M apresentam textura areia franca e assim, quando da comparação com os solos das parcelas C1M e SD1M, apresentam maior quantidade de areia na composição. A maior quantidade de areia torna estes solos mais susceptíveis aos processos erosivos devido a menor agregação destas partículas. A menor agregação favorece o destacamento das partículas pelas gotas das chuvas, tornando-as susceptíveis ao transporte pelo escoamento superficial. Além da característica textural, os Cambissolos presentes nas parcelas SD2M e C2M estão localizados em relevo de maior declividade, favorecendo a atuação do escoamento superficial e consequentemente dos processos de erosão hídrica.

$\mathrm{Na}$ bacia do ribeirão Jacutinga, as perdas na parcela SD2J foram de $45 \mathrm{t} \mathrm{ha}^{-1} \mathrm{ano}^{-1}$, valor superior ao limite tolerável de perdas de 4,15 $\mathrm{t} \mathrm{ha}^{-1} \mathrm{ano}^{-1}$. Quando da coleta de material, especialmente em períodos de menor índice pluviométrico, foram observadas fissuras na superfície dos Cambissolos junto à parcela SD2J. Por outro lado, ao longo de um evento pluviométrico, foi constatada a rápida formação de selo superficial e redução da infiltração da água da chuva, indicando a ocorrência de argilas expansivas (Figura 7c). Neste sentido, a textura argilosa associada à presença de argilas expansivas demonstra que os Cambissolos da parcela SD2J e C2J, quando mantidos descobertos, são altamente susceptíveis à erosão hídrica.

Apesar dos Cambissolos relativos às parcelas SD2J e C2J apresentarem alta susceptibilidade à erosão hídrica quando mantidos descobertos, as perdas observadas em todas as parcelas com cana-de-açúcar foram inferiores aos limites de tolerância (Tabela 2). Assim, houve redução considerável entre as perdas observadas nas parcelas com vegetação e as perdas das parcelas desprovidas de cobertura. Este cultivo foi responsável pela redução das perdas em $85,7 \%$ na parcela C1J e em 93,8\% na parcela C2J.

Ao longo do desenvolvimento das culturas de cana-de-açúcar foi observado decréscimo nas perdas de solo (Tabelas 3 e 4). Tal comportamento corrobora com a afirmação de Bertol et al. (2002) e Prochnow (2003), de que se espera que ocorra redução dos valores de razão de perdas de solo com o desenvolvimento das culturas. Bertol et al. (2002) avaliaram as perdas de solo em cultivos de milho e aveia, localizadas em Cambissolo Húmico alumínico argiloso e declividade média de 10\% (Lages, Santa Catarina). Já Prochnow (2003), no oeste paulista, determinou as perdas de solo e água na cultura do café, disposta em Argissolo Vermelho-Amarelo Eutrófico textura arenosa/média e declividade média de 10\%. Assim, mesmo sendo em 
condições físicas de paisagem e de cultivo, o desenvolvimento da vegetação proporciona, no geral, maior proteção ao solo.

Tabela 3: Valores de perdas de solo na parcela descoberta ajustados para a declividade média de $0,09 \mathrm{~m} \mathrm{~m}^{-1}$, razão de perdas de solo (RPS) e fator $\mathrm{C}$ em diferentes estágios culturais na bacia hidrográfica do córrego Monjolo Grande.

\begin{tabular}{c|c|c|c|c|c|c|c}
\hline Ciclo da cultura & FEI $_{\mathbf{3 0}}{ }^{(\mathbf{1})}$ & SD1M & SD2M & \multicolumn{2}{|c|}{ C1M } & \multicolumn{2}{c}{ C2M } \\
\hline & MJ/ha/ano & \multicolumn{2}{|c|}{$\mathrm{t} \mathrm{ha}^{-1}$ nno $^{-1}$} & RPS & Fator C & RPS & Fator C \\
\hline 1 & 436,13 & 3 & 15,55 & 0,52 & 0,0506 & 0,39 & 0,0382 \\
\hline 2 & 286,24 & 17,3 & 20,67 & 0,46 & 0,0295 & 0,36 & 0,0229 \\
\hline 3 & 3402,24 & 40,35 & 57,68 & 0,46 & 0,3493 & 0,44 & 0,3299 \\
\hline 4 & 285,25 & 0,46 & 0,58 & 0,02 & 0,0011 & 0,3 & 0,0193 \\
\hline 5 & 79,17 & 0,31 & 0,24 & 0,05 & 0,0009 & 0,45 & 0,0079 \\
\hline Total anual & $\mathbf{4 4 8 9 , 0 3}$ & $\mathbf{6 1 , 4 2}$ & $\mathbf{9 4 , 7 1}$ & $\mathbf{1 , 5 1}$ & $\mathbf{0 , 4 3 1 4}$ & $\mathbf{1 , 9 4}$ & $\mathbf{0 , 4 1 8 1}$ \\
\hline Solos & & $\mathrm{CX}$ & $\mathrm{CX}$ & \multicolumn{3}{|c}{$\mathrm{CX}$} & \multicolumn{2}{c}{$\mathrm{CX}$} \\
\hline Erodibilidade $^{\mathbf{( 2 )}}$ & & 0,084 & 0,088 & \multicolumn{3}{|c}{0,084} & \multicolumn{2}{|c}{0,088} \\
\hline
\end{tabular}

${ }^{(1)}$ Erosividade (MJ/ha/ano); ${ }^{(2)}$ Erodibilidade dos solos, presente em Corrêa (2016).

Tabela 4: Valores de perdas de solo na parcela descoberta ajustados para a declividade média de $0,09 \mathrm{~m} \mathrm{~m}^{-1}$, razão de perdas de solo (RPS) e fator $\mathrm{C}$ em diferentes estágios culturais na bacia hidrográfica do ribeirão Jacutinga.

\begin{tabular}{c|c|c|c|c|c|c|c}
\hline Ciclo da cultura & FEI $_{\mathbf{3 0}}^{(\mathbf{1})}$ & SD1J & SD2J & \multicolumn{2}{c|}{ C1J } & \multicolumn{2}{c}{ C2J } \\
\hline & & \multicolumn{2}{|c|}{ t ha-1 ano-1 } & RPS & Fator C & RPS & Fator C \\
\hline 1 & 69,9138 & 3,4606 & 1,1046 & 0,0814 & 0,0059 & 1,1099 & 0,081 \\
\hline 2 & 123,9896 & 0,2049 & 0,5715 & 0,8326 & 0,0217 & 0,3564 & 0,0093 \\
\hline 3 & 1879,085 & 2,804 & 22,351 & 0,4409 & 0,2005 & 0,0498 & 0,0351 \\
\hline 4 & 196,0554 & 5,5702 & 8,7441 & 0,0079 & 0,001 & 0,0191 & 0,0024 \\
\hline 5 & 230,6691 & 0,264 & 0,6702 & 0,0692 & 0,0051 & 0,0416 & 0,003 \\
\hline Total anual & $\mathbf{2 4 9 9 , 7 1 3}$ & $\mathbf{1 2 , 3 0 3 9}$ & $\mathbf{3 3 , 4 4 1 6}$ & $\mathbf{1 , 4 3 1 9}$ & $\mathbf{0 , 2 3 4 2}$ & $\mathbf{1 , 5 7 6 7}$ & $\mathbf{0 , 1 3 0 8}$ \\
\hline Solos & & PVA & CX & \multicolumn{2}{|c|}{ PVA } & \multicolumn{2}{c}{ CX } \\
\hline Erodibilidade & $(2)$ & & 0,061 & 0,047 & \multicolumn{2}{|c|}{0,061} & \multicolumn{2}{c}{0,047} \\
\hline
\end{tabular}

${ }^{(1)}$ Erosividade (MJ/ha/ano); ${ }^{(2)}$ Erodibilidade dos solos, presente em Corrêa (2016).

Com o desenvolvimento das culturas e maior proteção da superfície pela cobertura vegetal, menor será a ocorrência de erosão. Isto se deve à capacidade da vegetação em interceptar a água proveniente da precipitação, reduzindo o efeito da energia de impacto das gotas de chuva e consequentemente atenuando a destruição dos agregados, obstrução dos poros e selamento superficial (PRUSKI, 2009). Casseti (1991) salienta ainda que a cobertura vegetal tem papel frenador, dissipando a energia do material em deslocamento. A presença de obstáculos na superfície, oriundos da cobertura vegetal (porte arbóreo, gramínea, matéria orgânica), dissipa a energia do fluxo difuso e provoca a redução da capacidade de transporte e da atuação dos processos erosivos (FEITOSA, 2006; STYCZEN; MORGAN,1995).

No entanto, na parcela C2M verificou-se que, mesmo com o desenvolvimento e aumento da cobertura vegetal ao longo dos ciclos, não houve redução nos valores de RPS (Tabela 3). Tal característica demonstra que as condições naturais dos solos da parcela C2M e o atual uso e manejo inadequado favorecem a ocorrência de processos erosivos. 
Na bacia hidrográfica do córrego Monjolo Grande, os valores do fator $\mathrm{C}$ de ambas as áreas com cultivo de cana-de-açúcar foram superiores a 0,4. Os valores de RPS variaram de 0,393 a 0,521 para o período do plantio até 3 meses. Já no período de 10 a 12 meses, as RPSs variaram de 0,051 a 0,449 (tabela 3).

Para a quantificação das perdas de solo em nível de parcelas experimentais, muitos autores têm afirmado a necessidade do monitoramento por um período aproximado de 4 anos (LAFLEN, 1982), evitando-se assim a variabilidade dos dados. Mesmo considerando o período da presente pesquisa, os dados computados no primeiro ano experimental retratam, por ora, o comportamento altamente erosivo dos Cambissolos háplicos da bacia hidrográfica do córrego Monjolo Grande.

No que se refere ao fator $\mathrm{C}$, poucos são os estudos acerca do comportamento erosivo dos canaviais paulistas, destacando-se aqueles apresentados por Cavalieri (1998), De Maria et al. (1994) e Bertoni e Lombardi Neto (2010). No que se refere ao valor do fator C, Cavalieri (1998), a partir de comunicação pessoal de Francisco Lombardi Neto, apresenta o fator C de 0,31 para o período do plantio ao $1^{\circ}$ corte em cana-de-açúcar na região de Mogi Mirim (SP), em Latossolo vermelho amarelo e Argissolo vermelho amarelo, ambos de textura média, com declive variando de 0 a 12\%. Também, Cavalieri (1998) demonstrou que a RPS referente ao período do preparo ao plantio foi de 0,26 . Já no período de 9 meses ao $1^{\circ}$ corte a RPS foi de 0,10 .

De Maria et al. (1994), avaliaram 10 parcelas com cana-de-açúcar, localizadas no estado de São Paulo, em Latossolo de textura argilosa e Argissolo de textura média/arenosa e em declive variando de 0 a $3 \%$. Apresentaram RPS variando de 0,08 a 0,14 para o período do preparo ao plantio. Já para o período de 4 meses até a colheita, os valores de RPS variaram de 0,17 a 0,31. Os maiores valores de RPS estavam relacionados aos Argissolos de textura média/arenosa. Bertoni e Lombardi Neto (2010), a partir de dados preliminares da Seção de Conservação do Solo do Instituto Agronômico de Campinas (IAC), apresentaram RPS média de 0,15 para todo o $1^{\circ}$ ano, desde o plantio até a colheita da cana-de-açúcar em Latossolo Vermelho eutroférrico, textura argilosa.

Os resultados apresentados neste artigo bem como aqueles apontados por Cavalieri (1998), De Maria et al. (1994) e Bertoni e Lombardi Neto (2010) representam o mesmo tipo de cobertura vegetal e em estágio fenológico similar. No entanto, os maiores valores do fator $\mathrm{C}$, de 0,4 , observados junto às parcelas da bacia hidrográfica do córrego Monjolo Grande refletem as condições de elevada susceptibilidade erosiva dos solos associada ao maior declive do relevo. Assim, as condições naturais associadas ao uso com cana-de-açúcar propiciam a intensificação dos processos erosivos, degradação e depauperamento dos solos da região, além da intensificação de processos de assoreamento dos corpos hídricos do entorno.

Verifica-se que em toda a região de transição do relevo da Depressão Periférica Paulista com as Cuestas arenito basálticas está ocorrendo a acelerada expansão dos canaviais (CORRÊA et al., 2015). Neste sentido, considerando as elevadas taxas de perdas de solo e do fator $\mathrm{C}$ obtidos junto aos solos arenosos da bacia hidrográfica do córrego Monjolo Grande, a modificação do uso da terra verificada na região supracitada está ocasionando o rápido depauperamento dos solos da região.

$\mathrm{Na}$ bacia hidrográfica do ribeirão Jacutinga, as perdas foram de $0,8 \mathrm{tha}^{-1}$ ano $^{-1} \mathrm{e} 2,76 \mathrm{t} \mathrm{ha}^{-1} \mathrm{ano}^{-1}$ nas parcelas C1J e C2J e de 5,61 t ha- ano $^{-1}$ e $45 \mathrm{t} \mathrm{ha}^{-1}$ ano $^{-1}$ nas parcelas SD1J e SD2J (tabela 2). Os Cambissolos presentes nas parcelas SD2J e C2J apresentam elevada erodibilidade (0,047, tabela 4). Tal condição resultou em elevadas taxas de perdas de solo na parcela desprovida de vegetação. Também na parcela $\mathrm{C} 2 \mathrm{~J}$, no primeiro ciclo de desenvolvimento da cana-de-açúcar, foram observados valores elevados similares às perdas de solo da parcela descoberta. Com o desenvolvimento da cultura ocorreu maior proteção da superfície e, consequentemente, foram registradas menores RPSs (tabela 4).

As condições presentes na parcela $\mathrm{C} 2 \mathrm{~J}$ resultaram em um valor do fator $\mathrm{C}$ de 0,130 . Já na parcela $\mathrm{C} 1 \mathrm{~J}$ o fator $\mathrm{C}$ foi de 0,234 .

Para condições climáticas paulistas, Donzeli et al. (1992), a partir de dados da seção de conservação do solo (Instituto Agronômico de Campinas), em que as parcelas estão localizadas em declive de 0 a 3\%, apresentaram valores de fator $\mathrm{C}$ médio de 0,05 para os canaviais com incorporação da palha.

Nas mesmas condições físicas de paisagem apontadas por Cavalieri (1998), o fator C para a cana soca de $2^{\circ}$ e $3^{\circ}$ corte e com incorporação da palhada foi de 0,05 e 0,009 , respectivamente. Também para as mesmas condições apontadas por Bertoni e Lombardi Neto (2010), o fator C para o $2^{\circ}$ ano da cana soca foi de 0,015. Em Lousiana/EUA, em condições médias anuais de $1300 \mathrm{~mm}$ de precipitação, Bengston e Selim $(2007,2010,2012)$ obtiveram valores de fator $\mathrm{C}$ de $0,104,0,090$ e 0,084 para cada ano experimental para canaviais implantados em Neossolos Flúvicos franco siltosos. 
Apesar dos valores do fator $\mathrm{C}$ obtidos nas parcelas situadas na bacia hidrográfica do ribeirão Jacutinga terem sido inferiores àquelas situadas na bacia hidrográfica do córrego Monjolo, verifica-se que as parcelas $\mathrm{C} 1 \mathrm{~J}$ e $\mathrm{C} 2 \mathrm{~J}$ apresentaram fator $\mathrm{C}$ superior a alguns resultados presentes na bibliografia. Os fatores $\mathrm{C}$ apresentados na bibliografia foram obtidos em culturas implantadas em Latossolos e Neossolos flúvicos. Estes solos possuem condições naturais de maior condutividade hidráulica e profundidade, quando da comparação aos solos das parcelas C1J e C2J, tornando-os menos susceptíveis aos processos erosivos. Assim, os valores do fator $\mathrm{C}$ observados nestes solos, sob o cultivo de cana-de-açúcar e em condições fenológicas similares, são menores quando da comparação com os mesmos valores obtidos junto às parcelas C1J e C2J.

Na parcela C1J há um horizonte B textural diagnóstico dos Argissolos Vermelho Amarelos. Junto à parcela C2J observa-se a presença de argilas expansivas, textura argilosa e pequena profundidade efetiva dos Cambissolos Háplicos. Assim, as características físicas dos solos presentes nas parcelas C1J e C2J condicionam restrições à infiltração de água no perfil, favorecendo a ação do escoamento superficial e, portanto, da erosão hídrica condicionando maiores valores do fator $\mathrm{C}$.

\section{CONCLUSÕES}

1. Os solos arenosos da bacia hidrográfica do córrego Monjolo Grande apresentaram perdas elevadas, demonstrando que o uso e manejo inadequado da cultura de cana-de-açúcar estão ocasionando a rápida degradação dos solos sendo indicado o aperfeiçoamento do padrão de manejo da cultura ou a mudança no uso da terra. Como consequência, foram obtidos valores elevados do fator C. Este resultado demonstra que, mesmo em condições de cobertura do solo por culturas agrícolas onde se tem a proteção da superfície do solo por um determinado período, as condições físicas da paisagem favorecem o escoamento superficial e o destacamento e transporte de grandes quantidades de material erodido.

2. Os solos argilosos da bacia hidrográfica do ribeirão Jacutinga apresentaram perdas por erosão hídrica abaixo dos limites toleráveis, indicando que o atual uso e manejo da terra não promove a degradação dos solos por erosão hídrica. No entanto, considerando o mesmo ciclo produtivo ( $3^{\circ}$ corte com manutenção da palhada), verificou-se que as condições físicas dos solos argilosos resultaram em valores de fator $\mathrm{C}$ superiores àqueles presentes na bibliografia. Tal resultado demonstra que maior atenção deve ser dada ao manejo destes solos, visando à implantação de culturas que promovam a proteção da superfície.

3. A diversidade dos dados de RPS e fator $\mathrm{C}$ demonstra a necessidade de maior atenção à variabilidade $\mathrm{e}$ sensibilidade destes parâmetros na modelagem de perdas de solo, como na USLE. Também demonstra a necessidade de maiores estudos em condições diversas de paisagem e manejo.

4. Considerando a expansão dos cultivos de cana-de-açúcar no estado de São Paulo, especialmente em áreas de maior fragilidade ambiental como aquelas alocadas em solos rasos e de textura arenosa e tendo em vista as perdas superiores a 49,04 ton.ha ${ }^{-1}$ ano $^{-1}$, torna-se necessária a melhoria dos modelos de estimativa de perdas de solo visando o planejamento adequado do uso da terra.

\section{AGRADECIMENTOS}

À Fundação de Amparo à Pesquisa do Estado de São Paulo (FAPESP), pela bolsa de doutorado concedida e pelo apoio financeiro por meio do auxílio à Pesquisa - processo Fapesp 2012/19935-7; à Prefeitura Municipal de Ipeúna e à Coordenadoria de Assistência Técnica Integral - CATI, pelo apoio e suporte às atividades de campo e as Usinas de Açúcar e Álcool, Granelli e grupo Raízen, pelo apoio e concessão das áreas para a implantação dos experimentos.

\section{REFERÊNCIAS}

BENGTSON, R.L., SELIM, H.M. USLE "C" values for Louisiana sugarcane. ASABE Annual International Meeting, n. 12, 2007, 12 p.

BENGTSON, R.L., SELIM, H.M. USLE "C" values for Louisiana sugarcane. American Society of Agricultural and Biological Engineers. Annual International Meeting, ASABE, v. 1, 2010, p. 360-370.

BENGTSON, R.L., SELIM, H.M. USLE "C" values for Louisiana sugarcane American Society of Agricultural and Biological Engineers. Annual International Meeting, ASABE, v. 1, 2012, p. 199-213. 
BERTOL, I., ALMEIDA, J.A. Tolerância de perda de solo por erosão para os principais solos do Estado de Santa Catarina. Revista Brasileira de Ciência do Solo, Viçosa, v.24, n.3, 2000, p.657-668.

BERTOL, I.; SCHICK, J.; BATISTELA, O. Razão de perdas de solo e fator C para milho e aveia em rotação com outras culturas em três tipos de preparo de solo. Revista Brasileira de Ciência do Solo, Viçosa, n. 26, 2002, p. 545-552.

BERTONI, J.; LOMBARDI NETO, F. Conservação do solo. 7. ed. São Paulo: Editora Ícone, 2010.

BOARDMAN, J. Soil erosion science: Reflections on the limitations of current approaches. Catena, v. 68, 2006, p. 73-86.

CABEDA, M. S. V. Computation of storm EI Values. West Lafayette: Purdue University, 1976. 6p.

CARVALHO, N. O.; FILIZOLA JÚNIOR, N.P.; SANTOS, P.M.C.; LIMA, J.E.F.W. Guia de práticas sedimentométricas. Brasília: ANEEL. 2000. 154p.

CASSETI, V. Ambiente e apropriação do relevo. São Paulo: Contexto, 1991.

CAVALIERI, A. Estimativa da adequação de uso das terras da Quadrícula de Moji Mirim (SP), utilizando diferentes métodos. 1998. 112 f. Tese (Doutorado em Engenharia Agrícola). Faculdade de Engenharia Agrícola, Universidade Estadual de Campinas, Campinas, 1998.

COGO, N.P. Uma contribuição à metodologia de estudo das perdas de erosão em condições de chuva natural. I. Sugestões gerais, medição dos volumes, amostragem e quantificação de solo e água da enxurrada. 1a aproximação. In: ENCONTRO NACIONAL DE PESQUISA SOBRE CONSERVAÇÃO DO SOLO, 2., 1978, Passo Fundo. Anais... Passo Fundo: Empresa Brasileira de Pesquisa Agropecuária, 1978. p.75-98.

CORREAA, E. A. Perdas de solo e índices de vegetação: proposta metodológica para a determinação do fator C (MEUPS) em pastagens e cana-de-açúcar. 2016. 187 f. Tese de Doutorado (Doutorado em Geografia) - Instituto de Geociências e Ciências Exatas, Universidade Estadual Paulista, Rio Claro, 2016.

CORREA, E. A.; PINTO, S. dos A. F., COUTO JUNIOR, A. Espacialização temporal das perdas de solos em uma microbacia hidrográfica com predomínio de solos arenosos. Geografia, v. 40, n. 1, 2015a, p. 101-118.

CORRÊA, E. A.; MORAES, I. C.; PINTO, S. A. F. Estimativa da erodibilidade e tolerância de perdas em solos oriundos de arenitos e argilitos da região centro leste paulista. Geociências, v. 34, 2015b, p. 848-860.

COUTO JUNIOR, A. A. Erosão hídrica e transporte sedimentos na Bacia do Ribeirão Cachoeirinha (Rio Claro, SP). Universidade Estadual Paulista, Relatório interno, 2014.

DA SILVA, A.; SCHULZ, H. E. Estimativa do fator "C" da EUPS para cobertura morta de resíduos vegetais de origem urbana para as condições de São Carlos (SP, Brasil). Interciência, v. 26, n.12, 2001, p. 615-618.

DENARDIN, J. E. Erodibilidade do solo estimada por meio de parâmetros físicos e químicos. 1990. 113 f. Tese (Doutorado em Solos e Nutrição de Plantas) - Escola Superior de Agricultura Luiz de Queiroz, Universidade de São Paulo, Piracicaba, 1990.

DE MARIA, I.C.; LOMBARDI NETO, F. Razão de perdas de solo e fator C para sistemas de manejo da cultura do milho. Revista Brasileira de Ciência do Solo, v.21, 1997, p. 263-270.

DE MARIA, I.C.; LOMBARDI NETO, F.; DECHEN, S.C. F; CASTRO, O.M. Fator da equação universal de perdas de solo (EUPS) para a cultura de cana-de-açúcar. In: REUNIÃO BRASILEIRA DE MANEJO E CONSERVAÇÃO DO SOLO E DA ÁGUA, 10., 1994, Florianópolis. Anais... Florianópolis: Sociedade Brasileira de Ciência do Solo, 1994. p.148-149.

DONZELI, P. L.; VALÉRIO FILHO, M.; PINTO, S. A. F.; NOGUEIRA, F. P.; ROTTA, C. L.; LOMBARDI NETO, F. Técnicas de sensoriamento remoto aplicadas ao diagnóstico básico para o planejamento e monitoramento de microbacias hidrográficas. Campinas, Documentos IAC, v. 29, 1992, p.91-119.

DOORENBOS, J; KASSAM, A. H. Efectos del agua sobre el rendimiento de los cultivos. Roma: FAO, 1979. 212 p. (Estudio FAO: Riego y Drenaje, 33)

DOORENBOS, J.; PRUITT, J. O. Crop water requirement. Rome: FAO, 1977, 179p. (Irrigation and Drainage Paper, n. 24)

FEITOSA, M. V. Variação temporal do Índice de Vegetação (NDVI) correlacionada ao uso e manejo do solo para a estimativa da erosão. 2006. 128f. Dissertação (Mestrado em Agricultura Tropical e Subtropical). Instituto Agronômico de Campinas. Campinas, 2006. 
GARCÍA-RUIZ, J.M., BEGUERÍA，S., NADAL-ROMERO, E., GONZÁLEZ-HIDALGO, J. C., LANARENAULT, N., SANJUÁN, Y. A meta-analysis of soil erosion rates across the world. Geomorphology, v. 239, n.15, 2015, p. 160-173.

GUERRA, A. J. T. Processos erosivos nas encostas. In: CUNHA, S.B.;GUERRA, A. J. T. Geomorfologia Exercícios, Técnicas e Aplicações. $2^{\circ}$ ed. Rio de Janeiro: Bertrand Brasil, rio de Janeiro, 2005, p. 139-155.

KOPPEN, W. Klassification der klimate nach temperatur, niederschlag und jahreslauf. Petermanns Geographische Mitteilungen, Gotha, v. 64, 1918, p. 193- 203.

LAFLEN, J. M. Special problems of the USLE: soil erodibility (K). In: Workshop on estimating erosion and sediment yield on rangelands, 1., Tucson. Proceeding. Oakland: Agricultural Research Service, 1982. p. 63-72.

LOMBARDI NETO, F. Rainfall erosivity - its distribution and relationship with soil loss at Campinas, Brasil. 1977. Dissertação (Master of Sciente) - Purdue University, West Lafayette, 1977.

LOMBARDI NETO, F.; BERTONI, J. Tolerância de perdas de terras para solos do Estado de São Paulo. Campinas: Instituto Agronômico, 1975. 12p. (Boletim Técnico, 28).

LOMBARDI NETO, F.; SILVA, I. R.; CASTRO, O. M. Potencial de erosão de chuvas no Estado de São Paulo. In: ENCONTRO NACIONAL DE PESQUISA SOBRE CONSERVAÇÃO DO SOLO, 3., 1980, Recife. Anais... Recife: Sociedade Brasileira de Ciência do Solo, 1980. p.159.

MARENGO, J. A. O futuro clima do Brasil. Revista USP, n. 103, 2014, p. 25-32.

MORAES, I. C., CORRÊA, E. A. Avaliação de métodos de estimativa espacial para a interpolação de dados de erosividade em uma bacia hidrográfica utilizando métodos de geoestatística e técnicas de geoprocessamento In: SIMPÓSIO DE GEOTECNOLOGIAS NO PANTANAL, 3., 2010, Cáceres, MS. Anais... Cáceres: INPE, 2010.

PEREIRA, L. H.; PINTO, S.A.F. Utilização de imagens aerofotográficas no mapeamento multitemporal do uso da terra e cobertura vegetal na bacia do rio Corumbataí - SP, com o suporte de sistemas de informações geográficas. In: SIMPÓSIO BRASILEIRA DE SENSORIAMENTO REMOTO, 13, 2007, Flolrianópolis, SC. Anais eletrônico... São José dos Campos:INPE, 2007.

POESEN, J.; NACHTERGAELE, J.; VERSTRAETEN, G.; VALENTIN, C. Gully erosion and environmental change: importance and research needs. Catena, v. 50, 2003, p. 91-133.

PROCHNOW, D. Perdas de terra e água em sistemas de manejo na cultura do café no Oeste do Estado de São Paulo. 2003. 119f. Dissertação (Mestrado em Agricultura Tropical e Subtropical) - Instituto Agronômico de Campinas, Campinas, 2003.

PROCHNOW, D.; DECHEN, S. C. F.; DE MARIA, I. C.; CASTRO, O. M. de; VIEIRA, S. R. Razão de perdas de terra e fator $\mathrm{C}$ da cultura do cafeeiro em cinco espaçamentos, em Pindorama (SP). Revista Brasileira de Ciência do Solo, v.29, n.1, 2005, p. 91-98.

PRUSKI, F.F. Fatores que interferem na erosão hídrica do solo. In: PRUSKI, F.F., ed. Conservação de solo e água: Práticas mecânicas para o controle da erosão hídrica.2.ed. Viçosa, MG, Universidade Federal de Viçosa, 2009. p.41-74.

STYCZEN M. E.; MORGAN R. P. C. Engineering properties of vegetation. In: MORGAN R.P.C.; RICKSON R.J. Slope Stabilization and Erosion Control: A Bioengineering Approach. London: E\&FN SPON, p. 5-58, 1995.

UNICA. União dos Plantadores de Cana-de-açúcar de São Paulo. Estatísticas do Setor Sucroalcooleiro. Disponível em www.unica.com.br. Acesso em 06/03/2015.

VAN DER KNIJFF, J. M.; JONES, R. J. A.; MONTANARELLA, L. Soil Erosion Risk Assessment in Europe. Ispra: European Soil Bureau. Joint Research Centre. 2000.

WISCHMEIER, W. H. A rainfall erosion index for a universal soil-loss equation. Soil Science Society of America Proceedings, v.23,1959, p.246-249.

WISCHMEIER, W.H.; SMITH, D.D. Predicting rainfall erosion losses: a guide to conservation planning. Washington: United States Department of Agriculture, 1978, 57 p. (Agriculture Handbook, n. 537). 